\title{
Letters
}

Website: www.bmj.com

Email: letters@bmj.com

\section{Role of chief medical officer has indeed diminished}

Editor-Sir Donald Acheson's comments about how the post of chief medical officer for England has been diminished in recent years ${ }^{1}$ seem entirely right to me; my term as chief medical officer ended 25 years ago. The chief medical officer's function is not that of all-knowing medical expert but that of the coordinator and spokesperson for a balanced staff with links to the whole range of medicine and allied science. Formal and informal associations exist with other departments, especially in Scotland and Wales, and the World Health Organisation. The position must be even more complex than it was in my time.

The permanent secretary is head of the department, but the chief medical officer has always ranked with him or her since the Ministry of Health was established 80 years ago. I had friendly and fully cooperative relationships with four successive permanent secretaries, with the heads of other departments, and especially with the Medical Research Council. This would have been insupportable without the broadly based help of an able staff. Sir Donald's outspoken comments have my unqualified support.

George Godber Former chief medical officer

21 Almoners Avenue, Cambridge CB1 8NZ

1 Warden J. Role of UK chief medical officer has been eroded. BMJ 1998;317:1340. (14 November.)

\section{People should participate in, not be subjects of, research}

EDIToR-The use of the term "subjects" in the $B M j$ s structured abstracts conflicts with current research policy. A Medline review of BMJ structured abstracts published in 1997 revealed that 202 abstracts included the term "subjects" as a heading, with only three using the heading "participants." The standing advisory group on consumer involvement in the NHS research and development programme has recommended a "firm commitment to involving consumers in research-not as "subjects" of research, but as active participants in the process of deciding what research should take place, commissioning research, interpreting the results, and disseminating the findings., ${ }^{1}$

This view highlights inconsistencies between NHS research and $B M J$ editorial policy. The $B M J$ has previously emphasised patient (participant) involvement through method of study, ${ }^{2}$ and ethical concerns such as informed consent. ${ }^{3}$ Action is now required to change the terminology in structured abstracts and papers to reflect the role of people in the research process.

Petra M Boynton Research coordinator Department of Public Health, Kensington and Chelsea and Westminster Health Authority, London W2 6LX

1 Standing Advisory Group on Consumer Involvement in the NHS Research and Development Programme. Aim and values. Leeds: NHS Executive, 1998.

and values. Leeds: NHS Executive, 1998.
Jones R. Why do qualitative research? BMJ 1995;311:2.

2 Jones R. Why do qualitative research? $B M J 1995 ; 311: 2$.
3 Smith R. Informed consent: edging forwards (and 3 Smith R. Informed consent: edging forwa
backwards). BMJ 1998;316:949-51. (28 March.)

**We will be changing from "subjects" to "participants," except in rare cases where participant would be inappropriate. The new policy will be phased in from now.-Editor, $B M J$

\section{Resistance to antibiotics}

\section{Prescribing of antibiotics needs to be} rational

Editor-We agree with Hart that undergraduate and postgraduate medical education in the use of antimicrobials needs to be increased. ${ }^{1}$ Abbasi's news article ${ }^{2}$ is opposite a full page advertisement for an antibiotic. This advertisement seems to promote the use of a new fluoroquinolone to treat respiratory infections "even [due to] Streptococcus pneumoniae" in the community. Most strains of $S$ pmeumoniae remain sensitive to penicillin, and there is little evidence that quinolones are needed to treat acute sinusitis or acute exacerbations of chronic bronchitis.

The only other advertisement for an antibiotic in that edition of the $B M J$ occurs in the middle of a meta-analysis of antibiotic prophylaxis in critically ill people. ${ }^{3}$ The presence of these advertisements emphasises the likely difficulty in changing patterns of antibiotic prescribing.

Philip Pearson Senior house officer

Paul McWhinney Locum consultant physician

Philip Stanley Consultant physician

p.j.stanley@leeds.ac.uk

Regional Department of Adult and Paediatric Infectious Diseases, Seacroft Hospital, Leeds LS14 6UH

1 Hart CA. Antibiotic resistance: an increasing problem? BMJ 1998;316:1255-6. (25 April)

2 Abbasi K. Report calls for action on antibiotic resistance. BMJ 1998;316:1261. (25 April)

3 D'Amico RD, Pifferi S, Leonetti C, Torri V, Tinazzi A Liberati A. Effectiveness of antibiotic prophylaxis in critically ill adult patients: systematic review of randomised controlled trials. BMJ 1998;316:1275-85. (25 April.)

\section{Restricted prescribing resulted in} reduction of resistant strains

EdiTor-Abbasi's news article ${ }^{1}$ and Hart's editorial $^{2}$ about resistance to antibiotics raise interesting questions. Most antibiotics are prescribed in general practice, and how general practitioners deal with the problem of resistance is crucial. Resistance is closely related to the total amount of antibiotics prescribed and the proportion of broad spectrum antibiotics. In Finland, a high frequency of resistant streptococci has been reported, and a clinically significant reduction of resistant strains was found after recommendations for more restricted prescribing were implemented. ${ }^{3}$

In Norway, the prescription rate of antibiotics has risen by 40\% from 1980 to 1993 , but it is now declining. We have a minor problem with resistance to antibiotics in primary care. Pneumococci are still sensitive to phenoxymethylpenicillin, and the frequency of resistant Haemophilus influenzae has constantly been $10 \%$ of cases during the past years. The most likely reason for this favourable situation is the use of phenoxymethylpenicillin as the drug of choice for most common respiratory tract infections, such as acute otitis media, sinusitis, tonsillitis, and infections of the upper respiratory tract.

We believe that much can be done to reduce the use of antibiotics and that this may be of interest to other countries. Sixty per cent of all antibiotics are prescribed for infections of the respiratory tract, almost all in primary care. Antibiotics have been shown to be of little value in the treatment of acute otitis media and acute bronchitis. The treatment of patients with acute sinusitis is

\section{Advice to authors}

We prefer to receive all responses electronically, sent either directly to our website or to the editorial office as email or on a disk. Processing your letter will be delayed unless it arrives in an electronic form.

We are now posting all direct submissions to our website within 72 hours of receipt and our intention is to post all other electronic submissions there as well. All responses will be eligible for publication in the paper journal.

Responses should be under 400 words and relate to articles published in the preceding month. They should include $\leqslant 5$ references, in the Vancouver style, including one to the BMJ article to which they relate. We welcome illustrations.

Please supply each author's current appointment and full address, and a phone or fax number or email address for the corresponding author. We ask authors to declare any competing interest.

Letters will be edited and may be shortened.

www.bmj.com

letters@bmj.com 
still debated. ${ }^{4}$ Treatment should be given only during the first week of symptoms, as the disease in many cases is self limiting. The treatment of sore throat is also debated, and only patients with group A streptococci are in need of antibiotic treatment. The differential diagnosis and treatment in infections of the lower respiratory tract are difficult when the diagnosis is based on clinical evaluation alone. We have shown that a rapid test of $\mathrm{C}$ reactive protein, done in the general practitioner's office and providing an answer within 10 minutes, can be helpful in identifying patients who need to be treated with antibiotics. ${ }^{5}$ The test contributed to reducing the consumption of antibiotics by a quarter in our investigation. Another rapid test diagnosing group A streptococci is useful to assess patients with sore throat.

Paramedical reasons, such as forthcoming examinations or imminent holidays, can influence the amount of antibiotics prescribed. General practitioners should be aware of these factors and not accept them as a reason to presribe antibiotics.

Morten Lindbaek Associate professor

Per Hjortdahl Professor

morten.lindbak@samfunnsmed.uio.no

Department of General Practice, University of Oslo, N-0317 Oslo, Norway

Abbasi K. Report calls for action on antibiotic resistance. BMJ 1998;316:1261. (25 April.)

Hart CA. Antibiotic resistance: an increasing problem? BMJ 1998;316:1255-6. (25 April.)

3 Seppala H, Klaukka T, Vuopio-Varkila J, Moutiala A, Helenius H, Lager K, et al. The effects of changes in the consumption of macrolide antibiotics on erythromycin resistance in group A streptococci in Finland. N Engl J Med 1997;337:441-6.

4 Lindbaek M, Hjortdahl P, Johnsen UL-H. Randomised, double blind, placebo controlled trial of penicillin $\mathrm{V}$ and amoxicillin in treatment of acute sinus infections in adults. BMJ 1996;313:325-9.

5 Lindbaek M, Hjortdahl P. C-reactive protein in primary care-a useful diagnostic tool in infections. Tidsskr Nor Laegeforen 1998;118:1176-9.

\section{Expert controlling bodies need to be established}

EDITOR-Hart's editorial on antibiotic resistance asks questions that ignore scientific history. ${ }^{1}$ Thirty years ago the $B M J$ published a paper by Anderson on antibiotic resistance, its mechanisms of transmission, and implications, which embraced essential answers. ${ }^{2}$ This paper refers to the Swann committee, a temporary body then gathering evidence but dissolved in 1969 after it had reported an urgent need to limit antibiotic use in animal husbandry. Anderson's concluding emphasis was that the public health implications of antibiotic resistance are so serious that a powerful standing body is needed for medical and public protection. In the event, even the limited restrictions on antibiotic use imposed in Britain in the light of the Swann report proved so unpalatable to affected industries that pressure saw them quietly eroded after a change of government

A damaging gap in public health history and comprehension has since developed. The BMJ would do itself and the worlds of microbiology and medicine a great service were it to reprint this meticulous early paper. The clarity, power, and high quality of its science might stimulate the serious professional and government response that the problem requires. It seems extraordinary that, after 30 years, no standing expert controlling body has been established in Europe. Government and professional ambivalence together have allowed most of the predicted public health problems to become a worldwide reality, even though the practical and educational measures needed for effective control are attainable and remain unchanged. Research into drug resistance has moved forward and shown unexpected complexities in the mechanisms -for example, genetic interchangeability between bacterial and human cells ${ }^{3}$ - which could bring benefits. These will, however, resolve neither massive political inertia nor the scientific amnesia blocking progress on this important issue. Realisation that the fiscal costs of poor control of drug resistance are as high as the costs in human and animal misery is perhaps the trigger that will eventually set policy rolling.

Anthony Tucker Consulting science editor PATalban@aol.com

5 Spicer Street, St Albans, Hertfordshire AL3 4PH

1 Hart CA. Antibiotic resistance: an increasing problem? BMJ 1998;316:1255-6. (25 April.)

Anderson ES. Drug resistance in Salmonella typhimurium and its implications. BMJ 1968;iii:333-9.

3 van Veen HW, Callaghan R, Soceneantu L, Sardini A, Konings WN, Higgins CF. A bacterial antibiotic resistance gene that complements the human multidrug resistance p-glycoprotein gene. Nature 1998;391:291-5.

\section{Videos, photographs, and patient consent}

\section{Medical educationalists can free} themselves from constraints of "real world" images

EDiTor-Hood et al rightly emphasise that "the internet and electronic publishing are powerful tools for the dissemination of medical information and have created a demand for medical images" and that images of patients should, in most circumstances, not be used without consent. ${ }^{1}$ In the digital age, however, the links between images and individuals are complex and non-intuitive. With appropriate software it is easy to create images that do not reflect a true likeness of any real individual-cover girl images are

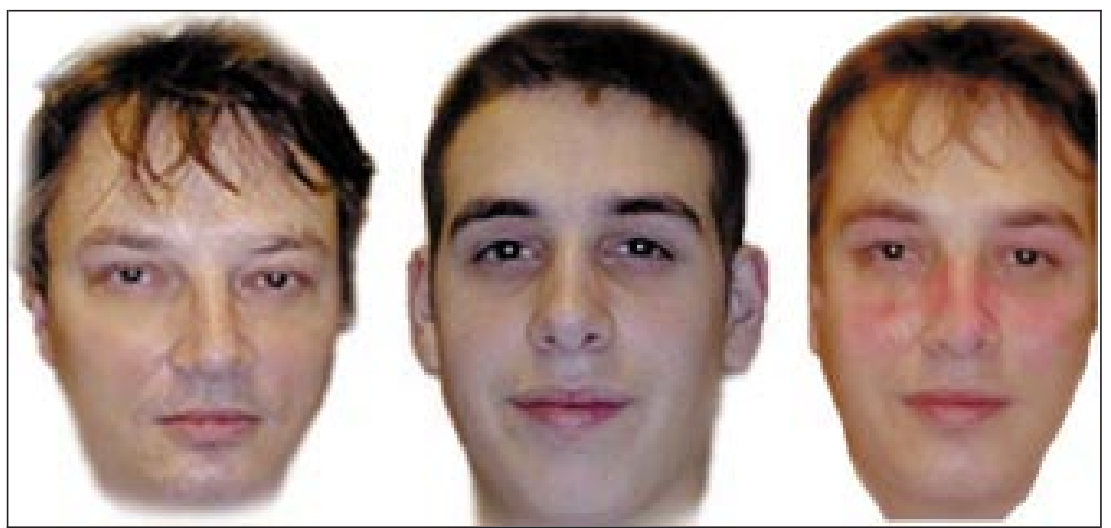

MorphMan was used to combine faces of both authors (left and centre) and then Photoshop was used to create a rash on the "combination" face (right) commonly touched up, O J Simpson can be turned into a blond, ${ }^{2}$ and Ronald Reagan can be given AIDS, complete with multiple Kaposi's lesions." Thus manipulation of digital images means that the potential of the internet in medical education need not be frustrated by ethical issues.

We wished to see whether we could, in a single afternoon, create fictional images of near-photographic quality illustrating medical conditions; we are interested amateurs and know that professional illustrators with more time and skill could achieve better results. We began by creating a malar butterfly rash such as one might see in systemic lupus erythematosus on a face that does not exist in the real world. To create the face we used the program MorphMan to combine the faces of both of us and then used Photoshop to create a rash on the "combination" face (figure). When we showed this image to a medical colleague he neither suspected that the rash was fake nor recognised us in the image. used images without consent. When multiple images are combined in this way, however, the final image is probably so far removed from any one patient as to obviate the need for consent. Had time permitted, we could have combined dozens rather than just three images. In such cases, use of how much of an image would warrant consent: would use of a single pixel require informed consent?

We conclude that in the age of Lara Croft (the virtual reality "star" of the Tomb Raider series) ${ }^{4}$ and Kyoko Date (the "virtual idol" created by engineers and designers of a Japanese model agency), ${ }^{5}$ medical illustrators and educationalists can begin to free themselves from the constraints of "real world" photographic images; the future is virtual.

Mark Pallen Senior lecturer

Nick Loman Web resources development officer Department of Medical Microbiology, St Bartholomew's and the Royal London School of Medicine and Dentistry, London EC1A 7BE m.pallen@qmw.ac.uk

1 Hood CA, Hope T, Dove P. Videos, photographs, an patient consent. BMJ 1998;316:1009-11. (28 March.)

2 www.wired.com/wired/3.09/images/oj.lrg.jpg

www.wired.com/wired/2.09/departments/elec.word.htm

4 www.cubeit.com/ctimes/lara.htm

5 www.etud.insa-tlse.fr/ mdumas/kyoko.html
One could argue that, in doing this, we 
Most patients agree to be videoed for teaching and publication purposes

EDITOR-Hood et al write about the electronic publication of images. ${ }^{1}$ We described similar methodology two years ago, ${ }^{2}$ and a copy of our consent form is available at http://medweb.bham.ac.uk/ http/depts / clin_neuro/teaching/consent. $\mathrm{html}$. We took advice from the General Medical Council, Medical Defence Union, Royal College of Physicians, BMA, local ethics committee, and legal department on the design of the form.

We were interested to read that Hood et al have found rates of acceptance similar to ours. Out of 169 patients approached prospectively over two years in this department of neurology, 154 agreed to be videoed for teaching and publication purposes (primarily for CD Rom, but also for use on the internet in a minority of cases). Many patients, especially older ones, have little precise knowledge of what a CD Rom and the internet are. We would therefore recommend that a laptop computer is used to allow fully informed consent to be obtained. The process takes time, but we have been encouraged by both our patients' enthusiasm and their help. One woman with dystonia agreed to be filmed for teaching purposes on the internet. Since it had taken nine years for her condition to be diagnosed, she was keen for anything that might help other doctors to learn about dystonia-so keen that she told fellow sufferers at a local meeting of the Dystonia Society about our project. One of them telephoned me the next day to ask if she could be filmed for a dystonia web page. We should not underestimate our patients' altruism.

David Nicholl Registrar

Department of Neurology, Queen Elizabeth

Hospital, Birmingham B15 2TH

d.j.nicholl@bham.ac.uk

David Davies Lecturer

Department of Physiology, Birmingham University, Birmingham B15 2TT

d.a.davies@bham.ac.uk

1 Hood CA, Hope T, Dove P. Videos, photographs, and patient consent. $B M J$ 1998;316:1009-11. (23 March.)

2 Nicholl D, Winters G, Davies D. Publishing information about patients. BMJ 1996;312:578-9.

\section{Medical images can be transferred by email}

EDITOR-We were interested to read of the case report on transferring images on a single patient via the internet ${ }^{1}$ as we have used email to send various clinical images on over 60 patients from a British field hospital in Bosnia and one of the navy's deployed warships to Royal Hospital Haslar so that a second opinion could be given. We have used a digital camera with a matrix size of $1280 \times 1024$ pixels (Olympus C1400L) to acquire good quality images of a wide variety of radiographs, dermatological problems and burns, electrocardiograms, and laboratory slides. Unlike the authors, we have found that a flat bed scanner is unnecessary, and we believe that email is the most suitable method of transmission as it is widely available and does not require a hospital to maintain a web server. We have found the technique neither complex nor time consuming.

We have reported our initial results, ${ }^{2}$ and we are currently undertaking a full analysis of the image quality, diagnostic accuracy, and clinical utility of our system. A camera based system is clearly both clinically versatile and suited to military use in remote locations. In one case we were able to provide a second opinion on a blood film when this system was used; other, vastly more expensive, telemedicine systems were unable to capture these images.

Exciting though the possibilities are for this simple technology, we would recommend some caution. Although the quality of the image is usually excellent, degradation occurs. These camera based systems must be regarded only as second opinions, and the original material must be reviewed. We agree with the authors that patient confidentiality is of paramount importance. We would advise that no information that identifies a patient is included in any email sent via the internet.

Examples of all types of images that have been transferred can be viewed on our website (http://ourworld.compuserve.com/ homepages/xray_haslar).

P J Buxton Surgeon commander, Royal Navy D J Vasallo Lieutenant colonel, Royal Army Medical Corps

J H Kilbey Wing commander

Department of Radiology, Royal Hospital Haslar, Gosport, Hampshire PO12 2AA

xray_haslar@compuserve.com

1 Johnson DS, Goel RP, Birtwistle P, Hirst P. Transferrin medical images on the world wide web for emergency clinical management: a case report. BMJ 1998;316:988-9. (28 March.)

2 Vasallo DJ, Buxton PJ, Kilbey JH, Trasler M. Defence medical services telemedicine.J R Army Med Serv (in press).

\section{Digital disguising techniques need to be improved}

EDITOR-Hood et al show a photograph in which the facial appearance has been disguised. $^{1}$ This technique, and the use of animated multiple squares for anonymous television interviews, is ineffective. By cutting down the information input by half-closing both eyes the viewer is able to recognise faces without any difficulty. I do not know the neurological explanation for this but presume that the simplification of the visual input enables the brain to retain the input for longer; the brain is able to summate the changes occurring in each square, and the brain can then summate the summations to produce a normal picture. These digital disguising techniques should be abandoned unless they can be improved.

Philip D Welsby Consultant physician

Regional Infectious Diseases Unit, Western General Hospital, Edinburgh EH4 2XU

1 Hood CA, Hope T, Dove P. Videos, photographs, and patient consent. BMJ 1998;316:1009-11. (23 March.)

\section{Consultants have sought to re-examine their contract}

EDITOR-In arguing for a new contract for consultants Richards confuses quality with quantity. ${ }^{1}$ Although both issues need to be addressed, the way to improve quality is through the more rigorous mechanisms for professional self regulation that are now being put in place. The contract of employment, however, is essentially about the quantum of work to be delivered; self regulation means that employers are then entitled to expect that this work is carried out to the highest standards. Under the current contract employers may be getting extremely good value and a change could lead to a reduced amount of work; the workload surveys undertaken for the Doctors' and Dentists' Review Board this year are likely to show that consultants work an average of around 50 hours a week in the NHS, as well as being on call-can employers really expect a greater commitment?

The Central Consultants and Specialists Committee agrees with Richards that the time is right to re-examine the consultant contract and that "consultants need an openly accountable and flexible contract." Last year we wrote to the NHS Executive asking to discuss how such changes could be achieved. Despite repeated requests the executive has not replied, though we hope to meet before the end of the year.

We differ from Richards on the need for consultants to have a contract that offers them-as well as the NHS-a degree of protection. Firstly, if consultants are expected to take on regular emergency rota commitments it is oversimplistic to argue that the working week is NHS time; time spent on call is an encroachment on personal life and must be explicitly recognised.

Secondly, any new contract will have to be less open ended than the current one to protect consultants from excessive workload. Not only is this required in implementing the European Commission's working time directive but today's consultants increasingly expect to be able to spend time with their families and to have a life outside the hospital.

Finally, the contract needs to be sufficiently flexible to enable consultants to carry out their wider professional activities because the ability to function as an independent professional as well as an employee is an important motivating factor for many consultants. Consultants increasingly believe that their contribution to the NHS is undervalued; in opening discussions with the executive we shall be looking for an arrangement which offers a fair deal both for patients and for consultants.

P C Hawker Chairman

Central Consultants and Specialists Committee, BMA, London WC1H 9JP

1 Richards P. Professional self respect: rights and responsibilities in the new NHS. BMJ 1998;317:1146-8. (24 October.) 


\section{More large trials needed to decide best duration of treatment with tamoxifen}

EDitor-I agree with Rea et al that we do not know the optimum duration of adjuvant tamoxifen treatment. ${ }^{1}$ The data that they presented, however, suggest that the trials they advocated-ATLAS (adjuvant tamoxifen longer against shorter) and aTTom (adjuvant tamoxifen treatment offers more?)-may still fail to resolve this issue. The most recent overview, which provides much indirect evidence, suggests that five years is better than two, but it also reports a non-significant trend for the incidence of endometrial cancer to rise with prolonged exposure to tamoxifen. ${ }^{2}$ The three randomised studies comparing five with 10 years suggest little added benefit for the extra years of tamoxifen; indeed one study reported a poorer disease free survival. ${ }^{3-5}$

When the ATLAS and aTTom studies are analysed the patients recruited in the early years will inevitably contribute more patient years and thus more events. Rea et al's data suggest that a much higher proportion of these early patients received tamoxifen for less than three years, a trend reversed more recently. Hence if the recent overview data reflect the true situation the half of these early patients randomised to five extra years of tamoxifen will show a considerable benefit. In contrast, the published data suggest that the more recently recruited patients, most of whom received over five years' treatment, may not show a similar benefit. As later recruits, however, they will contribute fewer events and may therefore have little impact on the trial outcome. There is therefore the distinct possibility of the false positive result that an extra five years' tamoxifen improves outcome.

Given the increasing trend to give tamoxifen for five years (as evidenced by the data reported by Rea et al), patients might be given around 10 years' treatment because of misleading trial results. Any impact on the incidence of endometrial cancer of the extra five years will probably not have been seen, as the number of women in the ATLAS and aTTom studies is smaller than that reported on in the recent overview. ${ }^{1}$ Indeed, the extra five years could be hazardous if the trend towards increasing endometrial cancer with prolonged duration is in fact real but only fails to be significant because of small numbers.

Clearly, trials on the scale of ATLAS and aTTom are needed, but the issue of the heterogeneity of the duration of tamoxifen treatment before recruitment needs to be addressed in the study design.

D A Cameron Senior lecturer in medical oncology Department of Oncology, Western General Hospital, Edinburgh EH4 2XU

1 Rea D, Poole C, Gray R. Adjuvant tamoxifen: how long before we know how long? BMJ 1998;316:1518-9. (16 May.)

2 Early Breast Cancer Trialists Collaborative Group Tamoxifen for early breast cancer: an overview of randomised trials. Lancet 1998;351:1451-67
3 Fisher B, Dignam J, Bryant J, DeCillis A, Wickerham D, Wolmark N, et al. Five versus more than five years of tamoxifen therapy for breast cancer patients with negative lymph nodes and estrogen receptor-positive tumors. J Nat Cancer Inst 1996;88:1529-42.

4 Tormey D, Gray R, Falkson H for the Eastern Cooperative Oncology Group. Post chemotherapy adjuvant tamoxifen therapy beyond five years in patients with lymph node-positive breast cancer. I Natl Cancer Inst 1996;88: $1828-33$

5 Stewart HJ, Forrest AP, Everington D, McDonald CC, Dewar J, Hawkins R. Randomised comparison of 5 years adjuvant tamoxifen with continuous therapy for operable breast cancer. The Scottish Cancer Trials Breast Group. Br J Cancer 1996;74:297-9.

\section{Community acquired pneumonia in elderly people}

\section{Addition of erythromycin is not currently justified}

EDITOR-I agree with Wort and Rogers that current British guidelines on community acquired pneumonia need revision, but I do not believe that the addition of erythromycin should always be considered in elderly people. ${ }^{1}$

They cite, as the basis for this recommendation, a study from Israel in which serological evidence of Chlamydia pneumoniae was found in $26 \%$ of cases of community acquired pneumonia in elderly people. ${ }^{2}$ It is not clear, in this or other similar studies, whether serological detection of $C$ pneumoniae indicates the cause of the pneumonia or whether treatment directed against it will make a clinical difference. More than one pathogen was identified in $30.4 \%$ (age $65-74$ ) and $37.8 \%$ (age $\geqslant 75$ ) of cases, but further details are not given. In the original publication other pathogens were also identified in the majority $(69 \%)$ of cases in which C pneumoniae was found (Streptococcus pneumoniae in $55 \%)^{3}{ }^{3}$

A high frequency of copathogens has been found in similar studies, suggesting that $C$ pneumoniae may simply initiate events while the other pathogen causes the pneumonia. Treatment with antibiotics to which $C$ pneumoniae is not sensitive leads to clinical recovery as quickly as when agents to which it is sensitive are given, ${ }^{4}$ supporting this viewpoint. A recent North American study, which included elderly patients, argued that there is no place for routine use of macrolides since only $7.5 \%$ of patients were found to have an organism that merited macrolide treatment and none of these patients died. ${ }^{5}$ Other pathogens for which a macrolide is first line treatment have been uncommon in other studies of community acquired pneumonia in elderly people. Disadvantages of concurrent macrolide treatment might include gastrointestinal and other side effects, drug interactions (for example, with theophylline), cost, and the development of macrolide resistance-already, in the United Kingdom; higher in the pneumococcus than for penicillins at $8.6 \%$ of isolates.

What is currently lacking most of all is evidence of the frequency of $C$ pneumoniae as a cause of community acquired pneumonia requiring specific treatment. No reliable data exist on the frequency of $C$ pneumoniae in the United Kingdom. Before recommending a macrolide in elderly people with community acquired pneumonia I would like to see a randomised controlled trial of $\beta$ lactam alone versus $\beta$ lactam plus macrolide. Until such data are available I suggest that macrolides should be used initially only in severely ill people (in combination with a $\beta$ lactam), especially when legionella infection is suspected.

Mark Woodhead Consultant in general and respiratory medicine

Department of Respiratory Medicine, Manchester Royal Infirmary, Manchester M13 9WL

Competing interests: I have acted as an adviser to many of the pharmaceutical manufacturers of antibiotics used in the treatment of community acquired pneumonia, including GlaxoWellcome, SmithKline Beecham, Abbott, Hoechst Marion Roussel, Rhone Poulenc, and Bayer.

1 Wort SJ, Rogers TR. Community-acquired pneumonia in elderly people. BMJ 1998;316:1690. (6 June.)

2 Lieberman D, Schlaeffer F, Porath A. Community-acquired pneumonia in old age: a prospective study of 91 patients admitted from home. Age Ageing 1997;26:69-75.

3 Lieberman D, Schlaeffer F, Boldur I, Lieberman D, Horow-

Lieberman D, Schlaeffer F, Boldur I, Lieberman D, Horowitz S, Friedman MG, et al. Multiple pathogens in adult patients admitted with community-acquired pneumonia: a one year prospective study of 346 consecutive patients.
Thorax 1996:51:179-84.

4 Kauppinen MT, Saikku P, Kujala P, Herva E, Syrjala H. Clinical picture of community-acquired Chlamydia pneumoniae pneumonia requiring hospital treatment: a comparison between chlamydial and pneumococcal pneumonia. Thorax 1996;51:185-9.

5 Mundy LM, Oldach D, Auwaerter PG, Gaydos CA, Moore RD, Bartlett JG, et al. Implications for macrolide treatment in community-acquired pneumonia. Chest 1998;113: $1201-6$.

\section{This pneumonia is only a small fraction} of all hospital cases of chest infection and pneumonia

EDITOR-Contrary to the editorial by Wort and Rogers, ${ }^{1}$ community acquired pneumonia is not the most common cause of acute hospital admission in any age group, including elderly people. In addition, their statement that 50000 cases occur each year in the United Kingdom is also misquoted and inaccurate. The study they refer to says, "Around 50000 people in the UK are admitted to hospital with pneumonia, making it one of the commonest causes of admission." These data come from NHS hospital statistics, which use the diagnostic code of the international classification of diseases (ICD9-CM), which unfortunately does not specify whether pneumonia is community acquired. As a result, hospital administrative data, even if they are taken at face value, are of limited use to find out different types of pneumonia.

Community acquired pneumonia has been defined in several ways. If the definition of the British Thoracic Society is used (an acute illness acquired in the community with a new (at least segmental) shadowing in the chest radiograph, and of no known cause or not an expected terminal event) such pneumonia is not the commonest category of chest infection admitted. In fact, a prospective study of community acquired pneumonia in 25 British hospitals over 13.5 months (1982-3) found only 511 adults (of these, 26 did not have pneumonia; age range was 15-74, with four patients outside this range 
being included). ${ }^{4}$ This gives an average enrolment rate per hospital per month of 1.4. Although this rate may seem widely different from the less controlled hospital data on pneumonia, most doctors familiar with acute hospital medicine would accept it as about right for a small to medium sized district general hospital.

In elderly people ( $\geqslant 65$ years old) the three commonest reasons for acute hospital admission are chest infection, falls, and inability to cope (including due to confusion). Most chest infection in elderly people is due to acute exacerbation of chronic obstructive lung disease, upper respiratory tract infection, non-pneumonic lower respiratory tract infection (bronchitic illness), and aspiration pneumonia. Only a small fraction of all chest infection and pneumonia (including nosocomial pneumonia) in hospital practice is community acquired pneumonia.

M Mamun Senior registrar

University Hospital Aintree, Liverpool L9 7AL

1 Wort SJ, Rogers TR. Community-acquired pneumonia in elderly people. BMJ 1998;316:1690. (6 June.)

2 British Thoracic Society. Guidelines for the management of community acquired pneumonia in adults admitted to hospital. Br J Hosp Med 1993;49:346-50.

3 Whittle J, Fine MJ, Joyce DJ, Lave JR, Young WW, Hough

$\mathrm{LJ}$, et al. Community acquired pneumonia: can it be defined with claims data? Am I Med Quality 1997;12: defined

4 British Thoracic Society. Community acquired pneumonia in adults in British hospitals in 1982-83: a survey of nia in adults in British hospitals in 1982-83: a survey of OJ Med 1987;62:195-220.

\section{Authors' reply}

EDITOR-We agree with Woodhead that the role of Chlamydia pneumoniae as an aetiological agent in community acquired pneumonia has to be more firmly established, especially in the United Kingdom, where the data on incidence are inadequate. However, in his recent review of guidelines on community acquired pneumonia from 10 European countries, $C$ pneumoniae was described as a causative pathogen in $12 \%$ of cases in adults, making it the second most common agent after Streptococcus pneumoniae. ${ }^{1}$ In combination with other atypical agents such as Mycoplasma pmeumoniae and Legionella spp, such organisms accounted for over $25 \%$ of cases of community acquired pneumonia. This is in discordance with the North American study cited by Woodhead, in which atypical agents accounted for only $7.5 \%$ of cases. ${ }^{2}$ Conclusions about treatment and outcome from this study must therefore be interpreted with caution. $C$ preumoniae often seems to be a copathogen and is found in particular with $S$ pneumoniae. ${ }^{3}$ The synergistic effect may be due to the ciliostatic effect of $C$ pneumoniae rendering the host more susceptible to the second agent. Patients infected with both $S$ pneumoniae and $C$ pneumoniae have a more severe illness. $^{4}$ Therefore $C$ pneumoniae seems not to just initiate events. In patients infected with both organisms treatment with agents that cover only $S$ pneumoniae results in a significantly longer hospital stay than that for patients infected with $S$ pneumoniae alone who are thus treated appropriately. ${ }^{4}$ Clearly further studies are needed to discover the exact role of $C$ pneumoniae in community acquired pneumonia, especially in elderly people who may have more severe disease. However, evidence suggests that it is important as a causative agent and that specific treatment with, for example, a macrolide is appropriate.

Mamun is correct to question our interpretation of the definition of community acquired pneumonia from the study by the British Thoracic Society. However, we suggest that a more accurate representation of the importance of pneumonia may be found in the large study performed by the Unit of Health-Care Epidemiology in Oxford. ${ }^{5}$ In the four age groups studied (1544, 45-64, 65-74, ₹75) between 1968 and 1986 only pneumonia and diabetes appeared in the top 10 most common conditions in every group. Pneumonia was the third most common condition in those aged $\geqslant 75$ and more common than chronic obstructive lung disease and other respiratory tract infections.

T Rogers Professor

Department of Infectious Diseases, Imperial College School of Medicine, Hammersmith Hospital, London W12 0NN

S J Wort Specialist registrar in respiratory and transplant medicine

Department of Transplant Medicine, Roya Brompton and Harefield NHS Trust, Harefield Hospital, Middlesex UB9 6JH

1 Woodhead M. Community-acquired pneumonia
guidelines-an international comparison. Chest 1998;113 guidelin

Mundy LM, Oldach D, Auwaerter PG, Gaydos CA, Moore $\mathrm{RD}$, Bartlett JG, et al. Implications for macrolide treatment in community-acquired pneumonia Chest 1998:113: $1201-6$

3 Lieberman D, Schlaeffer F, Boldur I, Lieberman D, Horowitz S, Friedman MG, et al. Multiple pathogens in adul patients admitted with community-acquired pneumonia: one year prospective study of 346 consecutive patient Thorax 1996;51:179-84.

4 Kauppinen MT, Saikku P, Kujala P, Herva E, Syrjala H. Clinical picture of community-acquired Chlamydia pneumoniae pneumonia requiring hospital treatment: comparison between chlamydial and pneumococca pneumonia. Thorax 1996;51:185-9.

5 Ashton CM, Ferguson JA, Goldacre MJ. In-patien workload in medical specialities. II. Profiles of individual diagnoses from linked statistics. OJ Med 1995;88:661-72.

\section{DNA methods should be used to detect Chlamydia trachomatis}

EDitor-We agree with the comments ${ }^{1}$ on Boag and Kelly's editorial ${ }^{2}$ about the recommendations made by the chief medical officer's expert advisory group on Chlamydia trachomatis. We wish to raise another issue.

The laboratories associated with the genitourinary medicine clinics in the two pilot projects evaluating the proposed screening will use molecular procedures (ligase chain reaction or polymerase chain reaction) and not the less sensitive tests (enzyme immunoassays) used by most laboratories testing for $C$ trachomatis in England and Wales. Support exists for this proposal. ${ }^{3}$ However, the use of the most sensitive tests should extend beyond this. About 30\% of women, symptomatic or asymptomatic, with $C$ trachomatis infection attending genitourinary clinics have small numbers of organisms in cervical specimens. ${ }^{4}$ As most clinics rely on enzyme immunassays the infection will not be diagnosed in most of these women. We calculate, on the basis of about 500000 women attending genitourinary medicine clinics each year, a prevalence of $C$ trachomatis of about $10 \%$, and about $30 \%$ of cases being missed, that in the past 10 years 150000 women seen in genitourinary medicine clinics will have had a $C$ trachomatis infection overlooked. There could not be a greater indictment of the service.

Some of these women may have received treatment, but most will have remained untreated and falsely reassured. Misdiagnosis is an important reason for $C$ trachomatis persisting in the community and the frequency of pelvic inflammatory disease, ectopic pregnancies, and infertility.

The usual justification for not using the sensitive detection tests is financial restriction. However, ultimately the introduction of DNA amplification tests will be cost effective. $^{5}$ The use of DNA amplification tests by laboratories servicing all clinics, not just those involved in the pilot projects, is long overdue. Pressure should be put on hospital trusts to make sure that the best tests are available. The medicolegal costs of infertility resulting from the failure to identify $C$ trachomatis because inferior tests were used will be high. The current situation would not be tolerated in HIV testing. $C$ trachomatis does not kill, but it causes an immense amount of human suffering.

David Taylor-Robinson Emeritus professor Department of Genitourinary Medicine and Communicable Diseases, Imperial College School of Medicine at St Mary's, London W2 1NY

Angela J Robinson Consultant phy sician Department of Genitourinary Medicine, Mortimer Market Centre, London WC1E 6AU

1 Screening for Chlamydia trachomatis [letters] BMJ 1998;317:680-2. (5 September)

2 Boag F, Kelly F. Screening for Chlamydia trachomatis. BMJ 1998;316:1474. (16 May.)

3 Simms I, Catchpole M, Robinson AJ, Laas C. Provision of diagnostic services for genital chlamydial infection in genito-urinary medicine clinics in England and Wales, 1996. Genitourin Med 1997;73:147-8.

4 Thomas BJ, Pierpoint T, Taylor-Robinson D, Renton AM. Quantification of Chlamydia trachomatis in cervical and urine specimens from women attending a genitourinary medicine clinic: implications for screening strategies. Int J STD/AIDS 1998;9:448-51.

5 Howell MR, Quinn TC, Braithwaite W, Gaydos CA. Screening women for chlamydia trachomatis in family planning clinics: the cost effectiveness of DNA amplifica tion tests. Sex Transm Dis 1998;25:108-17.

\section{Rigid following of dogma will not be best for all patients}

EDITOR-As general practitioners who run a training scheme we found the series "Getting research findings into practice" thought provoking. ${ }^{1}$ The most difficult part of general practice is arriving at a diagnosis, and the articles seem to start after the crucial decisions of general practice have been taken, after the art has been practised.

In 1948 Ryle wrote: "The three main tasks of the clinician are diagnosis, prognosis and treatment. Of these diagnosis is by far the most important, for upon it the success of the other two depend." Often the diagnosis of disease is much less objective 
than we as doctors would like and is not based on one simple test-consider angina, asthma, epilepsy, and depression. Patients often come with a loose amalgam of symptoms to their general practitioner, who tries to make sense of it with a mixture of open and closed questions, postures, pauses, and tests.

We have found it helpful to use a framework to explain why general practitioners' knowledge of patients is important. We believe that all patients have their own inherent set of predictive values, which may change with time according to their experience. Patients who consult infrequently are more likely to have disease with a given symptom than those who consult frequently in whom numerous investigations over the years have failed to identify clinically significant disease. General practitioners learn to assign increased validity to the concerns of an experienced mother. Doctors may have feared that every minor symptom they developed as students heralded the onset of a rare and life threatening syndrome, yet as qualified doctors they can ignore serious problems in themselves.

Predictive values of individual patients can help general practitioners determine the best course of action and enhance use of resources. They must not be used to deny patients tests or referrals, but they help in understanding the case and pre-empting results. Indeed, high predictive values are likely to facilitate earlier detection of disease. Patients with thin files merit great caution.

Students and house officers are often taught the blunderbuss approach to diagnosis: ask enough questions and organise enough tests and the "answer" will appear. We try to help doctors become aware of the bigger picture and not to rush in to assign labels of disease at an inappropriately early stage. We recognise that evidence based medicine demands the right questions and correct interpretation of answers but a rigid following of dogma will not be best for all patients.

Andrew Ross Course organiser

David Taylor Course organiser

South Birmingham Vocational Training Scheme,

Postgraduate Centre, Selly Oak Hospital,

Birmingham B29 6JD

1 Haines A, Donald A, eds. Getting research into practice [series]. BMJ 1998;317. (4 July- 22 August.)

2 Rye J. The natural history of disease. 2nd ed. Oxford: Oxford University Press, 1948.

3 Allibone A, Oakes D, Shannon H. The health and health care of doctors. J R Coll Gen Pract 1981;31:728-34.

\section{Managing infertility in general practice must include screening for sexual infections}

EDITOR-Hargreave and Mills failed sufficiently to emphasise the importance of sexually transmitted infections in their review on investigating and managing infertility in general practice. ${ }^{1}$ Genital tract infection with Chlamydia trachomatis is a major risk factor for subsequent tubal infertility. ${ }^{2}$ Many episodes of tubal infection can be asymptomatic ${ }^{3}$; those patients who have appreciable pelvic inflammation are just a small proportion of affected patients.

Two statements in particular concern us. Firstly, vaginal or other sexual infections cannot be reliably diagnosed by clinical examination alone. Ideally, anyone at risk of sexual infections should be referred for full assessment to a genitourinary medicine clinic, which offers diagnosis, treatment, and help with tracing sexual contacts.

Secondly, the authors seem to advocate testing an early morning specimen of urine from both partners for chlamydia plasmid DNA by the ligase chain reaction (although the reference quoted refers only to women). Testing urine by the ligase chain reaction seems attractive, but storage and processing are more complicated for urine samples than for swabs obtained from the cervix or urethra. The reported sensitivity of urine testing in women is as low as $70 \%$ when results are compared with a rigorous expanded gold standard, ${ }^{4}$ which simply emphasises that no single test can exclude genital chlamydial infection. The technology for ligase chain reaction tests is not available in all centres, and doing this test alone will miss concurrent sexual infections.

Finally, the issue of HIV testing of couples undergoing infertility treatment should have been discussed. Clinics' policy varies, but locally we have seen two couples found to be infected with HIV as part of the work up for in vitro fertilisation. Earlier recognition of risk factors and HIV testing would have prevented a dream becoming a nightmare so late in the day.

Andrew J Winter Specialist registrar

Department of Genitourinary Medicine, Whittall Street Clinic, Birmingham B4 6DH

Sameena Ahmad Consultant in genitourinary medicine

Bolton Centre for Sexual Health, Bolton BL4 0JR

1 Hargreave TB, Mills JA. Investigating and managing infertility in general practice. BMJ 1998;316:1438-41. (9 May.) 2 Paavonen J. Chlamydia trachomatis-a major threat to reproduction. Eur J Obstet Gynecol Reprod Biol 1993;49: 23-7.

3 World Health Organisation Task Force on the Prevention and Management of Infertility. Tubal infertility: serologic relationship to past chlamydial and gonococcal infection. Sex Transm Dis 1995;22:71-7.

4 Ridgway GL, Mumtaz G, Robinson AJ, Franchini M, Carder C, Burczak J, et al. Comparison of the ligase chain rartion with cell culture for the diagnosis of Che chain trachomatis infection in women. J Clin Pathol 1996;19: $116-9$

\section{Effectiveness of antibiotic prophylaxis in critically ill patients}

Distinction must be made between tracheal inflammation and pneumonia

Editor-It is ironic that D'Amico et al's meta-analysis of trials of antibiotic prophylaxis for respiratory infection ${ }^{1}$ appears in the same issue as the House of Lords' report on resistance to antibiotic drugs. ${ }^{2}$ D'Amico et al did not restrict diagnostic criteria and did not distinguish between tracheobronchitis and pneumonia in their analysis. Although this distinction can be difficult, it is worth recognising that colonisation of the trachea and tracheobronchitis are common but trivial events in intubated patients and are probably inevitable. Whether their prevention is worth while is doubtful.

It would be interesting to know the comparative prevalence of tracheobronchitis in the $16 \%$ of treated and $36 \%$ of control patients who had "respiratory infection" in the trials that D'Amico et al studied. Inappropriate prophylaxis contributes to the overuse of antibiotics. We should remain cautious about topical and systemic prophylaxis for respiratory infection in critically ill patients and continue to try to separate true lung infection from tracheal inflammation.

P J Sanderson Consultant microbiologist Edgware Community Hospital, Edgware, Middlesex HA8 0AD

1 D'Amico R, Pifferi S, Leonetti C, Torri V, Tinazzi A, Liberati A. Effectiveness of antibiotic prophylaxis in critically ill trials. BMJ 1998;316:1275-85. (25 April.)

2 Abbasi K. Report calls for action on antibiotic resistance BMJ 1998;316:1261. (25 April.)

\section{Selective decontamination offers no advantage}

EDitor-Our first comment on the study by D'Amico et al concerns the search through Medline. ${ }^{1}$ They have excluded a study by Godard et al, who conducted a double blind placebo controlled trial to test the efficacy of prevention of nosocomial infections by selective decontamination. ${ }^{2}$ Selective decontamination reduced the proportion of hospital acquired infections (33\%v60\%, $\mathrm{P}=0.02)$ and the number of cases of pneumonia ( $2 v 13$ cases, $\mathrm{P}<0.01)$. Selective decontamination alone, however, failed to reduce the proportion of infected patients $(26 \% v 34.5 \%, \mathrm{P}=0.20)$, mean duration of stay in hospital, and mortality.

The diagnosis of nosocomial pneumonia remains a source of considerable debate. For Gastinne et al, bacteriological documentation was not required (clinical approach). ${ }^{3}$ Other authors have used invasive procedures, but the lack of reliability of these techniques in the diagnosis of nosocomial pneumonia has recently been reported. ${ }^{4}$

Our last comment concerns the existence of bacterial samples that yield false negative results. Gastinne et al showed that $82 \%$ of tracheal aspirates contained detectable concentrations of antibiotics, which suggests that the microbiological criteria used to assess pneumonia may be unreliable. ${ }^{5}$ In the light of these methodological problems it seems difficult to report a potential advantage of selective decontamination to prevent pneumonia in critically ill patients.

B Allaouchiche Clinical fellow

H Jaumain Clinical fellow

D Chassard Associate professor

Intensive Care Unit, Hotel Dieu Hospital, F-69288

Lyons, France

1 D'Amico R, Pifferi S, Leonetti C, Torri V, Tinazzi A, Liberati A. Effectiveness of antibiotic prophylaxis in criticall Adult patients: systematic review of randomised con f randomised controlled trials. BMJ 1998;316:1275-85. (25 April.) 
2 Godard J, Guillaume C, Reverdy ME, Bachmann P, Bui-Xuan B, Nageotte A, et al. Intestinal decontamination in a polyvalent ICU. A double-blind study. Intensive Care Med 1990;16:307-11.

3 Gastinne H, Wolff M, Delatour F, Faurisson F, Chevret S. A controlled trial in intensive care units of selective decontamination of the digestive tract with nonabsorbable antibiotics. The French Study Group on Selective Decontamination of the Digestive Tract. N Engl J Med 1992;326:594-9

4 Papazian L, Thomas P, Garbe L, Guignon I, Thirion X, Charrel J, et al. Bronchoscopic or blind sampling techniques for the diagnosis of ventilator-associated pue

5 monia. Am J Respir Crit Care Med 1995;152: 1982-91. Gastinne H, Wolff M, Lachatre G, Boiteau R, Savy FP Antibiotic levels in bronchial tree and in serum during 1991;17:215-8.

\section{Antibiotic prophylaxis can lead to contamination with Clostridium difficile}

EDITOR-D'Amico et al suggested, on the basis of a systematic meta-analysis, that prophylactic topical and systemic antibiotics (cefotaxime) should be used to prevent pneumonia associated with ventilation. ${ }^{1}$ The rationale did not seem to consider complications, morbidity, or mortality in other patients in the ward or hospital, who might, as a result, develop the antibiotic induced complication of infection with Clostridium difficile. Such nosocomial infection can be lethal.

Contamination of the intensive care unit and hospital with $C$ difficile is another problem that D'Amico et al have not taken into consideration. Overuse of cefotaxime has been specifically implicated as a cause of such outbreaks. ${ }^{2}$ The mechanism of spread by contamination of the environment with spores $^{3}$ may be too high a price to pay in terms of morbidity, mortality, and cost benefit analysis. It can lead to ward closures and postponement of routine procedures and operations as a result of nosocomial infection

Daryl Leung Specialist registrar in general medicine and gerontology

Princess Royal Hospital, Telford, Shropshire TF6 6TF

1 D'Amico R, Pifferi S, Leonetti C, Torri V, Tinazzi A, Liberati A. Effectiveness of antibiotic prophylaxis in critically il adult patients: systematic review of randomised controlled adult patients: systematic review of rando
trials. BMJ 1998;316:1275-85. (25 April.)

2 Starr JM, Rogers TR, Impallomeni M. Hospital-acquired Starr JM, Rogers TR, Impallomeni M. Hospital-acquired
Clostridium difficile diarrhoea and herd immunity. Lancet 1997;349:126-8.

3 Leung DL. Hospital-acquired Clostridium difficile diarrhoea. Lancet 1998;349:1177.

\section{Authors' reply}

EdITOR-Unlike Sanderson, we find it interesting rather than ironic that our review was in the same issue of the House of Lords' report that was aimed at stimulating critical thinking against generalised fears of antimicrobial resistance. Critically ill patients undergoing ventilation are at high risk of pneumonia and death, and the issue whether or not they should be routinely treated with antimicrobials deserves great attention.

We accessed data on individual patients, which allowed us to ascertain that most patients in all trials were treated with antimicrobials at some point during their stay in an intensive care unit, regardless of the initial policy of the unit. The question is thus no longer whether, but rather when, they should be treated-immediately, as a policy, or only once their infection becomes clinically evident.

Sanderson states that tracheobronchitis is a trivial event for patients, which we disagree with. We checked the proportion of patients with pneumonia in our trials. In studies in which a topical and systemic combination was used, 10 out of 15 trials (1895 out of 2698 patients) considered only pneumonia: the proportion of patients with pneumonia was higher among the controls $(32 \%$ v 13\%). This is consistent with data from a previous meta-analysis, which showed that pneumonia was more frequent in the controls.

Allaouchiche et al believes that Godard et al's study should have been included in our review. ${ }^{2}$ We excluded it because it was not randomised. The two participating wards contributed to the study during two consecutive periods.

Diagnosis of nosocomial pneumonia remains a source of debate. In a previous paper we showed a similar reduction in the odds of infections, no matter whether or not a protected or distal technique or bronchoalveolar lavage was used or not to diagnose pneumonia (odds ratio 0.38 (95\% confidence interval 0.29 to 0.49$) v 0.36$ (0.29 to 0.44 ) respectively).

Leung warns about the danger of infection with Clostridium difficile. This is caused by overgrowth of $C$ difficile after long term use of systemic antibiotics. Topical prophylaxis as selective decontamination of the digestive tract usually does not include the type of new antimicrobials that work against the normal flora, and as these are excreted via bile and mucus into the gut they may induce $C$ difficile. Moreover, the most used systemic prophylaxis-cefotaxime treatment for a few days-has a minimal impact on resistance to colonisation. ${ }^{4}$ These observations seem to support our view that no trial showed a clinically significant harmful effect of selective decontamination of the digestive tract. These answers should help readers to distinguish between what is evidence based and what is still largely "opinion based."

Roberto D'Amico Research fellow

Laboratory of Health Services Research and Italian Cochrane Centre, Mario Negri Institute, 20157 Milan, Italy

Silvia Pifferi Research fellow

Ospedale Maggiore, Istituto di Ricovero e Cura a Carattere Scientifico (IRCCS), Milan, Italy

\section{Alessandro Liberati Head}

Institute of Biostatistics, Medical School, University of Modena, Modena, and Italian Cochrane Centre, Mario Negri Institute, 20157 Milan, Italy

1 Heyland DK, Cook DJ, Jeascher R, Griffith I, Lee HN Guyatt GH. Selective decontamination of the digestive tract: an overview. Chest 1994;105:1221-9.

2 Godard J, Guillaume C, Reverdy ME, Bachmann P, Bui-Xuan B, Nageotte A, et al. Intestinal decontamination in a polyvalent ICU. A double-blind study. Intensive Car Med 1990;16:307-11.

3 Selective Decontamination of the Digestive Tract Trialists' Collaborative Group. Meta-analysis of randomised controlled trials on selective decontamination of the digestive tract BMJ 1993;307:525-32

4 Vollaard EJ, Cleasener HAL, Janssen AJHM. Influence of cefotaxime on microbial resistance in healthy volunteers. JAntimicrob Chemother 1990;26:117-23.

\section{Rationing}

Introduce new category of prescription charges, "full cost medicines"

EDITOR-In the wake of the controversies surrounding the approval of sildenafil citrate $^{12}$ and orlistat $t^{3}$ perhaps the time has come for the introduction of a new category of NHS prescription drugs, "full cost medicines." Such medicines would be prescribed by the patient's general practitioner, but the patient would pay the full cost plus the dispensing fee. This system would have many advantages, including maintaining the relationship between the general practitioner and the patient, suppressing misuse of expensive and possibly recreational drugs, keeping down the cost of such medicines because of the purchasing power of the NHS, and educating patients about the cost of pharmaceutical products and thus potentially opening up the debate on rationing of health care.

This proposal is not as radical as it sounds. We already have a model for such a system in the provision of NHS dentistry, with patients being expected to pay the full cost of their treatment up to a maximum of $£ 340$. If this charge is acceptable for the maintenance of dental health surely around $£ 5$ is acceptable for the maintenance of sexual health.

Peter Ramsay-Baggs Consultant oral and maxillofacial surgeon

Ulster Hospital, Dundonald, Northern Ireland

BT16 0RH

omfs@compuserve.com

1 Smith R. Viagra and rationing. BMJ 1998;317:760-1

(19 September.)
Brooks A. Viagra is licensed in Europe but rationed in Britain. BMJ 1998;317:765. (19 September.)

3 Brooks A. Obesity drug is licensed in the UK. BMJ 1998;317:835. (26 September.)

\section{The word must be used and the} government must give a stronger lead

EDITOR-I applaud the $B M f_{\text {s }}$ consistency over time in proclaiming the need for the rationing debate to be more explicit ${ }^{1}$ and to involve the public, as has happened elsewhere. What we have so far failed to address is how the current government may be let off the hook it is stuck on through not being prepared to use the word "rationing." As general practitioners contemplate involvement in primary care groups and local healthcare cooperatives they need political leadership. Those who still live in the comfort of being only patient's advocate or hoping for further increases in health expenditure must face up to the reality that exists the world over in developed countries and persuade this government to share the responsibility for making choices and creating priorities as best we can, now.

I wish to retain my patients' trust but need that sharing of responsibility with the government, purchasers, colleagues, and the public in a spirit of honest doubt and where there are few black and white decisions to be made.

Philip Gaskell General practitioner

31 Eyre Crescent, Edinburgh EH3 5EU administrator@GP70304.lothian-hb.scot.nhs.uk

1 Smith R. Viagra and rationing. BMJ 1998;317:760-1. (19 September.) 


\section{Medical students' electives abroad}

\section{Students need extensive advice on planning electives}

EDITOR-Banatvala and Doyal's editorial on student electives abroad raised several issues. ${ }^{1}$ As the elective tutor at the Royal Free Hospital School of Medicine I am responsible for ensuring the wellbeing of each student going on an elective both in the United Kingdom and abroad. Time has to be spent with each student, discussing every aspect of their plans and identifying potential problems. This includes considering their academic suitability, the occupational risks and, importantly, travel related hazards.

Students choose to gain medical experience in various settings. Some wish to experience health care in a rural setting, others in a university teaching hospital. Students must be aware of the differences in setting and learning experience. Some may be shocked to find few medical resources and may be expected to act as a fully qualified medical practitioner. Others may be disappointed to find that they gain little "hands on" experience other than shadowing the duty doctor. The experience that a student hopes to gain from the elective must be discussed to highlight any potential difficulties.

The possibility of culture shock, language difficulties, and loneliness are among other subjects that need to be addressed. Advice should be given on immunisations, antimalarial prophylaxis, and other general methods of prevention of illness. The necessity of comprehensive travel and health insurance must be emphasised.

Students are encouraged to write a report on their experiences during the elective, which is subsequently read by fellow students. It is hoped that in this way students will have an appreciable overview of what to expect, not only from the place but also from the clinical experience and teaching. The interaction with other students and the social activities available are also an important consideration.

Medical students need to receive comprehensive and appropriate advice about their elective placement. An "electives evening" is held annually for the students at this medical school. A comprehensive publication on electives in collaboration with the Medical Defence Union is also available.

A series of articles on how to plan your elective was published in the studentBMJ. ${ }^{3}$ This initiative started with an editorial followed by a series of articles focusing on all aspects of the elective in several countries accompanied by an article written by a medical student reporting their own experiences there. ${ }^{4}$

I hope that the above mentioned will encourage medical students to seek advice that should be readily available in their own medical schools, thus ensuring that each student enjoys the experience of the elective.

Jane Zuckerman Elective tutor

Royal Free Hospital School of Medicine, London NW3 2PF
1 Banatvala N, Doyal L. Knowing when to say "no" on the student elective. BMJ 1998:316;1404-5. (9 May.)

2 Zuckerman JN, Medical Defence Union. Electives-An essen tial guide for students. London: MDU, 1997.

3 Westall J,Zuckerman JN. How to plan a clinical attachment abroad. studentBMJ 1998:6; 5 .

4 Westall J, Zuckerman JN. Uganda-Planning your elective. Westall J, Zuckerman $J$.

\section{Some care is better than none at all}

EDITOR-Banatvala and Doyal's article reminded me of my experiences while on elective in India in 1992. I assisted a British general practitioner in a village clinic set up to improve local health and do longitudinal studies into health problems in the area. On arrival I was informed that the doctor was staying for two weeks to show me the ropes. After that I was on my own for three months as Action Health 2000 couldn't provide another doctor.

I was terrified initially-I was $150 \mathrm{~km}$ from civilisation, had no one to talk to apart from the paramedic who spoke English, was living in a mud hut village with intermittent electricity, having to share a room with three Indian men, and had to deal with problems I'd never heard of, nor knew how to treat. I had 60 different drugs to use, could do basic tests to diagnose anaemia, malaria, tuberculosis, infections of the urinary tract, could measure erythrocyte sedimentation rates, and had a large supply of textbooks. At weekends I visited hospitals in the city to attend clinics to learn various physical signs and treatments so I could further help the villagers.

One person died while I was there (not my fault but I felt guilty for some time), and I made many people better or improved their quality of life. Sometimes I didn't know what to do-but is that any different from now? The only difference was that I had no one to ask.

Had I refused to take this on I would have missed the most amazing experience of my life. I learnt how to take responsibility and make decisions - even if they turned out to be wrong-and deal with the consequences. I learnt where to find information and how to use it. I improved the lives of people who had no other medical care available. I grew up a lot. All these things are important to being a doctor, but most people learn them when they are already house officers. On my return, I was better at dealing with patients, and able to behave in a more mature and decisive manner.

Ethically, it is difficult to say that it is OK for medical students to take on such responsibilities when they are not fully trained. Morally, however, can you justify the closure of a population's only local healthcare centre for three months just because the only person available hasn't got his or her final degree? Why should people have to suffer without care of any description? Surely some care is better than none at all?

Heather Harris Senior house officer, surgical rotation Medway Hospital, Gillingham, Kent ME7 5NY

1 Banatvala N, Doyal L. Knowing when to say "no" on the student elective. BMJ 1998:316;1404-5. (9 May.)

\section{Those who are qualified to help should} help

EDITOR-I work in a rural hospital in a developing country and was interested to read Molloy's account of his student elective in India, ${ }^{1}$ with the accompanying editorial advocating the drawing up of clinical guidelines for similar periods of overseas elective experience. ${ }^{2}$ Banatvala and Doyal challenge the legitimacy of the assumption that "some help is better than no help" and suggest that if a life saving intervention is needed, the medical student should act simply as a good citizen and do his or her best. In the following week's $B M J$, I was fascinated to read the discussion surrounding a doctor who, having had an alcoholic drink, intervened in the care of a patient with a possible neck injury. ${ }^{3}$ Presumably Cressey attended the sporting event primarily as an "ordinary citizen," but found himself unable to avoid the ethical obligation laid on him as a doctor, despite the less than ideal circumstances. In the accompanying commentaries Walsh says that doctors can never renounce their duty to help should the need arise; and Rigter and de Beaufort say that drawing up guidelines on alcohol use for doctors off duty (or for their subsequent actions) would be virtually impossible.

Although medical students are not doctors, they nevertheless find themselves in situations such as Molloy's where, even if viewed as ordinary citizens, they are in possession of knowledge and capabilities that surely place them under a moral obligation to use their skills to help those in need. In addition, if it is perceived as difficult to draw up guidelines on alcohol use for doctors off duty, then I believe that it will be doubly difficult to draw up meaningful and enforceable clinical guidelines for medical students working in developing countries. Adequate supervision seems to be a minimum requirement, but the sheer number of patients, the extreme nature of their illnesses, and the often unpredictable variations in hospital staffing levels are just a few of the factors militating against the reliable implementation of practical guidelines.

I realise that part of the ethicist's task is to advise on standards that all of us should strive to achieve; but when faced with a situation where there is an obvious need, and there is someone available who can address that need (whether a slightly inebriated doctor, an inexperienced medical student, or a conscientious citizen) then, as thousands could surely testify, some help-if it's truly help-is indeed better than no help.

James K Torrens Physician

Chogoria Hospital, Chogoria, Kenya, Africa

\footnotetext{
1 Molloy K. Plunged in at the deep end. BMJ 1998;316: 1466-7. (9 May.)

2 Banatvala N, Doyal L. Knowing when to say "no" on the student elective. BMJ 1998:316;1404-5. (9 Mav.)

3 Cressey DM. Ethanol, emergencies and ethical dilemmas. [With commentaries by Walsh and Rigter and de Beaufort]. BMJ 1998:316:1515-6. (16 May)
} 